\section{Un futuro para la luz urbana}

Pascal Chautard Presidente DIA, Diseñadores de Iluminación Asociados
Hoy, las ciudades y sus espacios exteriores son recorridos por sus habitantes y visitantes tanto de noche como de día. Se vuelve primordial el desarrollo de planes de iluminación urbana con el fin de caracterizar zonas, ordenar las circulaciones y dar lugar a nuevos usos y maneras de entenderlas.

Las ciudades no solo viven de día. La duración de la noche, en Santiago por ejemplo, varía aproximadamente desde 9 horas en verano a 14 horas en invierno. Los cambios de hábitos respecto al pasado han provocado la extensión de las actividades del ser humano: los habitantes siguen activos utilizando el espacio urbano varias horas después del anochecer. Esta situación da cuenta de la pertinencia de una reflexión acerca de la incorporación de una imagen nocturna urbana coherente.

La iluminación del espacio urbano es un acto relativamente reciente en la historia de las ciudades. En París, el alumbrado público sistemático nació realmente a fines del s. XVI, cuando el rey Louis xIV concedió la compagnie des flambeaux al abate Caraffa. Al terminar el s. xvII París contaba con 6.500 puntos de iluminación que funcionaban con aceite A inicios del s. xviI se realizaron los primeros ensayos con gas, pero fue con la llegada de la electricidad, a fines del s. xIx, que el alumbrado de la ciudad vivió una revolución. Junto con la electricidad llegó el fantasma de la iluminación absoluta; en ese entonces se pensó que era posible iluminar la ciudad de noche, tal como si fuera de día, y permitir así distinguir cualquier detalle a pesar de la oscuridad. Esto fue, obviamente, sin cuantificar la descomunal cantidad de energía que se necesitaría.

A principios del s. xx, el alumbrado público se comenzó a encaminar hacia soluciones más modestas. De hecho, la aproximación de la iluminación de las urbes estuvo por muchos años enfocada, principalmente a alumbrar las vías de tránsito de los automóviles, de modo que estos puedieran recorrerlas a cierta velocidad, con relativa seguridad y una calidad de visión que les permitiera distinguir a los peatones.

Este alumbrado, elaborado por ingenieros y luminotécnicos, desarrollaba "el nivel de iluminancia promedio." Esto provoca que las ciudades sean cubiertas por un sistema de iluminación estrictamente funcional, que no toma en cuenta su estética, su imagen nocturna ni la experiencia del transeúnte que vive la ciudad de noche. Hasta hoy, muchas son las urbes que siguen con este patrón de iluminación y que solo cuentan con indicios de alguna iluminación de monumentos realizada en forma totalmente aleatoria y que no contribuye a la conformación de una imagen nocturna coherente.

A partir de la segunda mitad de la década de 1980 se desarrolla, principalmente en Europa, una reflexión sobre cómo abordar la ciudad de noche debido, entre otros factores, a la entrada de las ciudades en la era de la comunicación, la búsqueda de una identidad propia por parte de los municipios, la toma de conciencia de los habitantes que representan votos en las elecciones municipales, la necesidad imperativa de controlar los gastos en energía, el desarrollo del turismo y la recuperación de barrios industriales o sociales.

Los proyectos de planificación urbana integran paulatinamente un nuevo componente: l' urbanisme lumière o urbanismo luz, que se mate-
Today, the cities and their exterior spaces are circulated by their inhabitants and visitors both day and night. The development of urban lighting plans with the object of characterizing zones give order to circulation and place to new uses and ways of understanding becomes fundamental.

rializa a través de nuevas herramientas, como son los lighting master plans o planos directores de iluminación. Estos permiten que los poderes políticos de las ciudades puedan disponer de elementos de análisis, tanto cualitativos como cuantitativos, de los sistemas de iluminación urbana y planificar, en el mediano y largo plazo, las inversiones relativas a alumbrado público.

A pesar de ello hasta hoy, la inmensa mayoría de las ciudades latinoamericanas siguen presentando una apariencia poco atractiva de noche. En el mejor de los casos cuentan con un sistema de iluminación de calles funcional pero los ambientes nocturnos resultan bastante pobres para las personas, con apenas algunos monumentos puestos en valor y casi ningún proyecto de iluminación arquitectónica integral.

Esta situación de escaso desarrollo podría transformarse en una oportunidad para pensar una nueva iluminación para las ciudades latinoamericanas en el futuro y crear imágenes nocturnas coherentes, que las transformen en lugares más atractivos para sus habitantes y visitantes. Es, además un buen momento para disminuir en forma drástica los consumos energéticos asociados a la iluminación urbana, así como también los costos de mantenimiento, en base al empleo de nuevas tecnologías y el desarrollo de proyectos con un nivel de diseño superior y distintivo.

Estas transformaciones no pueden ser ejecutadas a ciegas o sobre la base de la improvisación, sino que deben ser desarrolladas por profesionales capaces de hacer las preguntas específicas a las nuevas imágenes nocturnas propias para cada ciudad latinoamericana. De esta manera, el plan director de iluminación urbana representa una figura necesaria e interesante para que los municipios puedan afirmar claramente la voluntad de crear un nuevo paisaje nocturno.

En ese contexto, el urbanismo luz se transforma en una necesidad para planificar y hacer rentables las inversiones en iluminación; reunir las iniciativas necesarias para impulsar el embellecimiento de la ciudad; definir un marco legal para la implementación de la iluminación pública y privada; transmitir una nueva imagen nocturna local hacia los medios nacionales o internacionales; desarrollar un turismo nocturno diferente, que muestre la riqueza de la ciudad a sus habitantes, además de brindar un sentimiento de orgullo y la sensación de pertenecer a un territorio común.

PLAN DIRECTOR DE ILUMINACIÓN URBANA / El fin de un plan es valorizar la estructura urbana, remarcando y jerarquizando la multiplicidad de vías y funciones que existen, con la utilización de las diversas variables que posee la materia luz; luminancias, temperatura de color, índice de reproducción cromática, altura de soporte y otros.

La materia luz puede acentuar o modificar la percepción o la imagen que se tiene de un lugar al participar plenamente de una "poética 


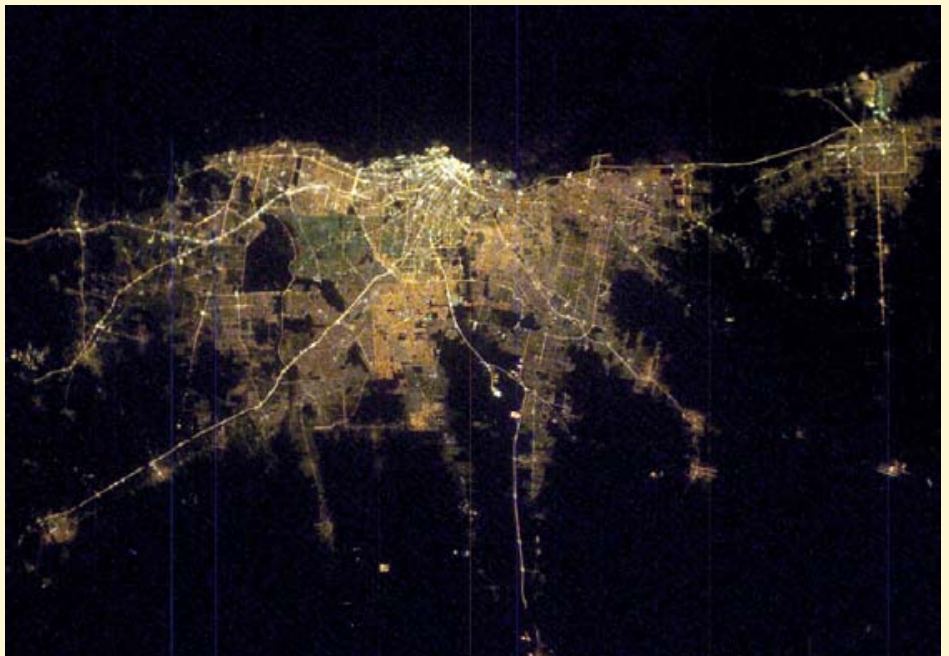

01 Vista nocturna de Buenos Aires, 2003

Fuente: Earth Observatory, nasa. En: http://earthobservatory.nasa.gov/IOTD/view.php?id=3295

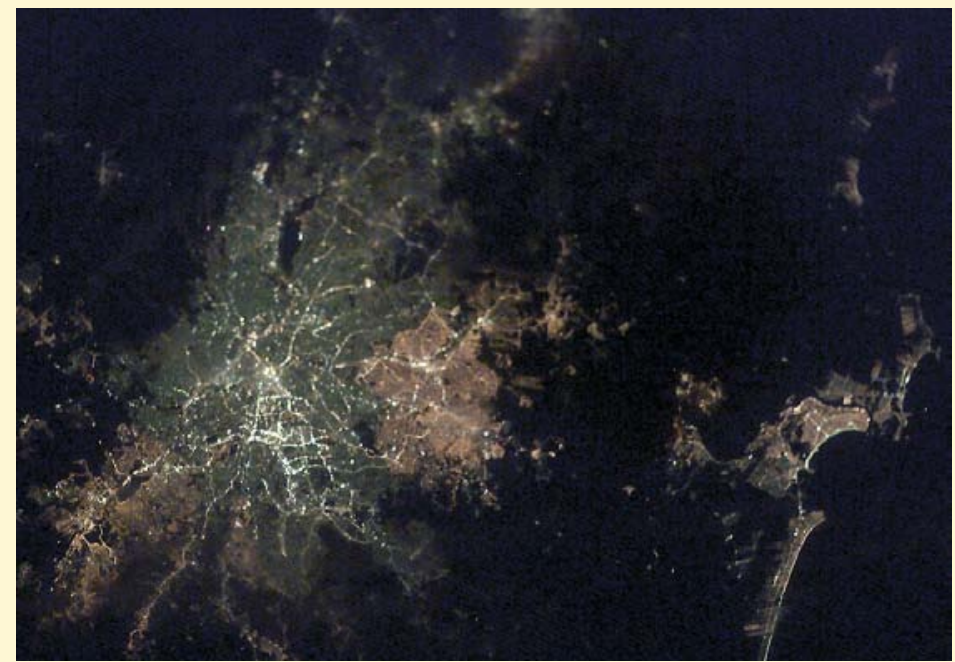

02 Vista nocturna de São Paulo, 2003. Fuente: Earth Observatory, nasa.

En: http://earthobservatory.nasa.gov/images/imagerecords/3000/3427/ISS006-E-44689_Irg.jpg espacial" con la utilización de referentes sociológicos y culturales. Bajo este punto de vista, un plan director ordena los diferentes tipos de iluminación para llegar a una "escena de iluminación" propia de cada ciudad, que no es más que la visión nocturna de esta, que evidencia el paisaje urbano y sus componentes, tales como ríos, jardines, monumentos y otros. Al mismo tiempo, organiza los espacios de acuerdo a su función, ya sea residencial, comercial o administrativa.

Todo el orden descrito obedece a un principio estratégico general que es similar al utilizado por los arquitectos y urbanistas en los planos reguladores dado que, al igual que en este tipo de labores, la solución se obtiene luego de una reflexión tanto cualitativa como cuantitativa sobre el análisis de las variables implicadas en una ciudad, tales como: su historia, morfología, arquitectura, flujo de actividades y realidad existente.

Entre los objetivos del plan director de iluminación urbana es importante crear una imagen nocturna global coherente, además establecer una jerarquía en función de los diversos espacios de la ciudad, los ejes de comunicación principales y secundarios, los distintos barrios, sus características específicas, su uso y su valor patrimonial. También es relevante que dicho plan logre armonizar y unificar en el mediano plazo los sistemas de alumbrado público y permita la creación de la imagen diurna y nocturna deseada de la ciudad. Por otra parte, el plan debe ser capaz de modernizar los sistemas de iluminación existentes, eliminar fuentes sucias o poco eficientes, generar ahorros en los costos de operación principalmente por la disminución de consumos y ahorros en mantenimiento a través de la implementación de equipos de iluminación eficientes. Se deben integrar también las nociones de ahorro de energía y de sustentabilidad en alumbrado público, lo que significa buscar mejores soluciones técnicas para conseguir los efectos deseados. En suma, se trata de iluminar lo justo: limitar los fenómenos de contaminación lumínica, no crear situaciones de sobre-iluminación y utilizar equipos de gran eficiencia, así como fuentes lumínicas de larga vida útil y fácil mantenimiento.

Adicionalmente, los ahorros realizados por la aplicación del plan regulador de iluminación deben permitir financiar en parte importante las inversiones a realizar los siguientes años. Los objetivos específicos, así como la programación de las distintas fases de aplicación del plan, deberán ser definidos en conjunto con el equipo de trabajo municipal.

El plan debe ser dirigido idealmente por un concepteur lumière o diseñador de iluminación independiente tanto de los fabricantes como de las empresas proveedoras de energía, en colaboración dinámica con los equipos políticos y técnicos del municipio, es decir, alcalde, consejeros municipales, director de obras municipales, arquitectos, urbanistas, ingenieros del servicio de alumbrado público y sociólogos, entre otros. El desafío es grande y depende mucho de la toma de conciencia de los poderes políticos de los municipios, en cuanto permitan ciudades más acogedoras después de la puesta del sol. ARQ 